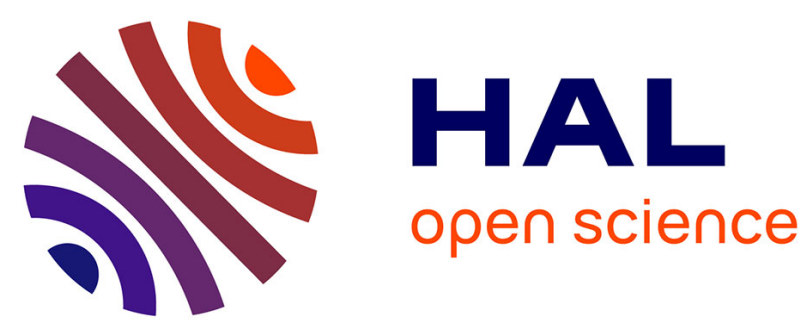

\title{
A method to assess glyphosate, glufosinate and aminomethylphosphonic acid in soil and earthworms
}

Olivier Delhomme, Anaïs Rodrigues, Ana Hernandez, Supansa Chimjarn, Colette Bertrand, Marjolaine Bourdat-Deschamps, Clémentine Fritsch, Céline Pelosi, Sylvie Nélieu, Maurice Millet

\section{To cite this version:}

Olivier Delhomme, Anaïs Rodrigues, Ana Hernandez, Supansa Chimjarn, Colette Bertrand, et al.. A method to assess glyphosate, glufosinate and aminomethylphosphonic acid in soil and earthworms. Journal of Chromatography A, 2021, 1651, 10.1016/j.chroma.2021.462339 hal-03322696

\section{HAL Id: hal-03322696 https://hal.inrae.fr/hal-03322696}

Submitted on 10 Nov 2021

HAL is a multi-disciplinary open access archive for the deposit and dissemination of scientific research documents, whether they are published or not. The documents may come from teaching and research institutions in France or abroad, or from public or private research centers.
L'archive ouverte pluridisciplinaire HAL, est destinée au dépôt et à la diffusion de documents scientifiques de niveau recherche, publiés ou non, émanant des établissements d'enseignement et de recherche français ou étrangers, des laboratoires publics ou privés.

$$
\text { Copyright }
$$


1 A method to assess glyphosate, glufosinate and aminomethylphosphonic acid in

4 Olivier Delhomme ${ }^{1,2}$, Anaïs Rodrigues ${ }^{1}$, Ana Hernandez ${ }^{1}$, Supansa Chimjarn ${ }^{1}$, Colette

5 Bertrand $^{3}$, Marjolaine Bourdat-Deschamps ${ }^{4}$, Clémentine Fritsch ${ }^{5}$, Céline Pelosi ${ }^{6}$, Sylvie

6 Nélieu $^{4}$, Maurice Millet ${ }^{1}$

${ }^{1}$ Université de Strasbourg, CNRS-UMR 7515, ICPEES, 67087, Strasbourg, France.

$9 \quad{ }^{2}$ Université de Lorraine, 57070, Metz, France.

${ }^{3}$ Université Paris-Saclay, INRAE, AgroParisTech, UMR ECOSYS, 78026, Versailles, France.

$11{ }^{4}$ Université Paris-Saclay, INRAE, AgroParisTech, UMR ECOSYS, 78850, Thiverval-Grignon,

12 France.

$13{ }^{5}$ Laboratoire Chrono-environnement, UMR 6249 CNRS - Université de Franche-Comté Usc

14 INRAE, 16 route de Gray 25030 Besançon cedex, France.

${ }^{6}$ INRAE, Avignon Université, UMR EMMAH, 84000, Avignon, France.

\section{Abstract}

A new sensitive and selective analytical methodology to quantify glyphosate (GLY), aminomethylphosphonic acid (AMPA), and glufosinate (GLU) in both soil and earthworms

21 (Allolobophora chlorotica) was developed. The extraction and purification methods were optimized. The samples were extracted with various aqueous solutions $\left(\mathrm{HNO}_{3}, \mathrm{H}_{2} \mathrm{O}, \mathrm{KOH}\right.$ and borate buffer) and derivatized with 9-Fluorenylmethyl chloroformate (FMOC-Cl). To optimize the extraction step, a method to remove the excess FMOC-Cl was applied based on liquid-liquid extraction with diethyl ether. The purification of derivatized extracts was carried out using XLB solid phase extraction (SPE) cartridges before internal standard quantification 
27 by liquid chromatography coupled to tandem mass spectrometry (LC/MS/MS). The elution 28 step was optimized to obtain the best recoveries possible, which was with acidic methanol 29 (1\% formic acid) (67\% for GLY, $70 \%$ for GLU and $65 \%$ for AMPA). The extraction and 30 purification method followed by analysis of the two herbicides and AMPA in soils using 31 LC/MS/MS determined limit of quantification (LOQ) values of $0.030 \mu \mathrm{g} \mathrm{g}^{-1}$ for GLY, $320.025 \mu \mathrm{g} \mathrm{g}^{-1}$ for AMPA and $0.020 \mu \mathrm{g} \mathrm{g}^{-1}$ for GLU . For earthworms, LOQ were $0.23 \mu \mathrm{g} \mathrm{g}^{-1}$ 33 for GLY, $0.20 \mu \mathrm{g} \mathrm{g}^{-1}$ for AMPA and $0.12 \mu \mathrm{g} \mathrm{g}^{-1}$ for GLU. .

34 The developed method was applied to determine these compounds in natural soils and 35 earthworms.

37 Keywords: herbicides, soil organisms, liquid chromatography-tandem mass spectrometry, 38 solid-phase extraction, derivatization. 


\section{Introduction}

The non-selective herbicide glyphosate is currently the major organophosphate herbicide used worldwide [1]. Since its introduction as an active herbicide ingredient in 1971, the worldwide market for GLY has continuously increased, with a noticeable boost after 1990 due to the worldwide introduction of genetically modified crops [2]. Indeed, together with ammonium glufosinate, another broad-spectrum herbicide, they are extensively applied on a large variety of crops (e.g., cereals, vineyards, potatoes, peas, orchards) as well as in nonagricultural areas such as private gardens and industrial areas. One reason for this intensive use is their high efficacy against most weeds and affordable price compared to other herbicides.

In the environment, GLY is rapidly degraded into aminomethylphosphonic acid, its major metabolite. In water, degradation mainly results from photodegradation [3], and in soil from microbial biodegradation [4]. GLU and GLY are considered to be non-persistent field halflives $\left(\mathrm{DT}_{50}\right)$ of 7 and 24 days, respectively, whereas AMPA is persistent, with a field $\mathrm{DT}_{50}$ of 419 days [5]. However, some evidence suggests that GLY may be more persistent than expected, with detection in runoff following spraying and rainfall several months after application. There are also reports that glyphosate-based herbicides have the potential to persist in the environment for up to 197 days after a single application [1]. Thus, intensive use of GLY and GLUbased herbicides can strongly disperse the active ingredient in the environment and has the potential to contaminate the environmental compartments i.e., water [6], soil [7], air [8] and organisms. GLY and AMPA, in particular, have both been frequently found in surface waters [[2], [9]].

The accumulation of GLY, GLU and AMPA in living soil organisms has so far only been assessed in snails [10]. Earthworms are prey for numerous predators [11] and key soil organisms as they influence soil structure, organic matter dynamics, and plant productivity 
67 [[12], [13]]. These soil organisms are used as models in ecotoxicology and several studies have assessed the impact of GLY, AMPA or GLU on them [[14], [15]]. It has been recognized that although commercial formulations containing GLU and GLY generally have no effects on mortality, they may negatively impact earthworm enzyme activities, body weight, reproduction, behavior (avoidance, foraging) and activity (surface casting) [[16], [17]]. For instance, GLY has been reported to modify earthworm feeding behaviour and thus to alter ecological interactions between earthworms, mycorrhizal fungi, and aboveground plants [18]. However, bioaccumulation of these compounds in earthworms has never been assessed even though it could give new insights into their potential ecotoxic effects on these organisms and the consequences on soil functioning.

Detection of the potential presence of these herbicides in the environment has required the development of specific analytical procedures because measurement of their residues is challenging [19]. Indeed, the analysis of these molecules in environmental matrices remains difficult with conventional detectors such as UV and fluorescence due to the lack of adequate chemical groups in GLY, its metabolite AMPA and GLU molecules (i.e. chromophores or fluorophores). In addition, their ionic character, complex formation with metals [[20], [21], sorption to glassware [22], low volatility and insolubility in organic solvents associated with their low molecular mass has increased the analytical difficulties, in particular the low quantification limits required for water quality criteria.

Many analytical procedures have been developed in the last decades for the quantification of GLY, AMPA and GLU including gas chromatography after a derivatization step [[23], [24]], ion chromatography coupled with conductimetry [25] or inductively coupled plasma spectrometry [[26], [27]] and liquid chromatography coupled to fluorescence and/or mass spectrometry [[28], [29], [30], [31], [32]]. FMOC- $\mathrm{Cl}$ is the most common derivatization agent used, as it allows, when associated with LC/MS/MS, a better detection and 
quantification than non-derivatized herbicides. Indeed, it results in improved chromatographic separation from the matrix, as well as superior selectivity and sensitivity [33]. However, even if LC/MS/MS is a reliable method for quantifying GLY, GLU and AMPA at low detection levels, their extraction from soils and living organisms is complicated by the matrix. It is known that, in soil, these herbicides show high sorption to soil clays and organic matter [21]. Several extraction methods from soil have been reported [[4], [24], [34]] but in many cases, the extraction method was specific for one type of soil [31], and to our knowledge no extraction methods have been reported for earthworms.

In the present study, a new sensitive analytical methodology to quantify GLY, GLU and AMPA residues in both soils and earthworms (Allolobophora chlorotica) using SPE - LC ESI - MSMS was developed. As the quantification of GLY, GLU and AMPA residues in earthworms is original as never published elsewhere in our knowledge, for soils a particular attention was made, regarding previous works, to optimize the extraction and purification methods, especially by testing various aqueous solutions for extraction and elution mixtures after purification by SPE. This fully characterized method was applied on soil and earthworms samples.

\section{Material and methods}

\subsection{Chemicals and solutions}

HPLC grade quality solvents (acetonitrile (ACN), ethanol, diethyl ether, methanol $(\mathrm{MeOH})$, n-hexane), potassium hydroxide $(38 \%)$ Normapur $(\mathrm{KOH})$, disodium tetraborate decahydrate (borate), ammonium hydroxide solution $\left(\mathrm{NH}_{4} \mathrm{OH}\right)$ and formic acid solution (HCOOH) were purchased from VWR Prolabo (Paris, France). Formic acid, ACN and water for LC/MS were purchased from Sigma Aldrich (LPCR, France). The ultra-pure water was obtained through a Milli-Q system $(18 \mathrm{M} \Omega \mathrm{cm})$ from Merck, Germany. FMOC-Cl and 
117 dimethyl-dichloride silane (DMDCS) were purchased from Fluka and Aldrich, respectively 118 (l'Isle d'Abeau, France).

119 High purity pesticide standards (>98\%) were supplied by Cluzeau Info Labo (Sainte-Foy-

120 la-Grande, France) for GLU (ammonium 2-amino-4-(hydroxymethylphosphinyl)butyrate;

121 CAS number: 77182-82-2) and by Sigma Aldrich (l'Isle d'Abeau, France) for GLY (N-

122 (phosphonomethyl)glycine; CAS number: 1071-83-6), AMPA (aminomethylphosphonic acid;

123 CAS number: 1066-51-9) and internal standards: APPA (1- aminopropyl phosphonic acid;

124 CAS number: 14047-23-5) and AMPPA (1- amino-2-methylpropyl phosphonic acid; CAS

125 number: 66254-55-5).

126 Stock solutions of each pesticide at $1 \mathrm{~g} \mathrm{~L}^{-1}$ and calibration standard solutions were 127 prepared in ultra-pure water and stored in silanised glassware or plastic flasks. A saturated 128 solution of $50 \mathrm{~g} \mathrm{~L}^{-1}$ borate buffer $\left(\mathrm{pH}\right.$ 9) in ultra-pure water and a solution containing $10 \mathrm{~g} \mathrm{~L}^{-1}$ 129 of FMOC-Cl in ACN were used for the derivatization step prior to LC/MS/MS analyses.

130 All glassware in contact with GLY, GLU and AMPA was silanized. The solution for 131 glassware silanization was prepared by diluting 5\% DMDCS in n-hexane. After 10 min of 132 contact, glass containers were rinsed twice with hexane then with $\mathrm{MeOH}$ before being dried in 133 a fume hood.

\subsection{Earthworm and soil sampling}

136 The earthworm Allolobophora chlorotica (green morph) was chosen as a model organism.

137 This earthworm species is common in temperate European regions and was chosen because it

138 lives close to the soil surface. It is thus potentially highly exposed to and impacted by 139 pesticides [35]. For method development, characterization and matrix-matched calibration 140 curves, pesticide-free earthworms were collected by hand from a fallow in Versailles, France $141\left(48^{\circ} 48^{\prime} 31^{\prime \prime} \mathrm{N}, 2^{\circ} 05^{\prime} 26^{\prime \prime} \mathrm{E}\right)$. The fallow had not been treated with pesticides for more than 20 
142 years. The individuals were used as the blank matrix and first analyzed to confirm the absence

143 of contamination with the targeted pesticide residues.

144 For method application, A. chlorotica individuals were manually collected in Spring 2016 by

145 superficially digging the soil in winter wheat fields located in the Long-Term Socio-

146 Ecological Site Zone Atelier Plaine \& Val de Sèvre (ZA-PVS;

147 http://www.za.plainevalsevre.cnrs.fr/) [36]. Earthworms were then stored for $48 \mathrm{~h}$ in Petri

148 dishes on damp filter paper to void gut contents and then frozen at $-80{ }^{\circ} \mathrm{C}$ until analysis.

149 Soil cores were also sampled in the same wheat fields as the earthworms using a $5 \mathrm{~cm} \varnothing$

150 soil auger at a $0-5 \mathrm{~cm}$ depth. The soils were frozen at $-20^{\circ} \mathrm{C}$ before being analyzed. One part

151 of some soil samples was used for method development. For this, they were extracted with

152 water, in order to remove potential traces of herbicides, and dried at $50^{\circ} \mathrm{C}$ overnight in an

153 oven. They were again extracted with pure water and analyzed for GLY, GLU and AMPA

154 content. If none of these molecules were present, the soil samples were used for method 155 development.

\subsection{Soil extraction}

158 Soil samples were defrosted and $30 \mathrm{~g}$ collected and removed from roots and small stone 159 debris. Each sample was then homogenized by slight crushing and $15 \mathrm{~g}$ were put in a plastic

160 container (Figure 1) and spiked with the internal standards (IS) APPA and AMPPA (40 $\mu$ L of

161 each at $10 \mathrm{mg} \mathrm{L}^{-1}$ ). To allow the sorption of the IS onto the soil structure, the mixtures were

162 left in the dark for one hour (sufficient time for a total sorption) before starting the extraction

163 procedure.

164 After this delay, $20 \mathrm{~mL}$ of the extraction solution $\left(10 \mathrm{~mL}\right.$ borate buffer $\left.+10 \mathrm{~mL} \mathrm{H}_{2} \mathrm{O}\right)$ was

165 added and the sample was stirred for one hour at room temp in the dark on a magnetic stirrer, 166 followed by centrifugation at $1252 \mathrm{~g}$ for 30 minutes. The supernatant (extract 1) was 
collected and the soil sample was re-extracted with $10 \mathrm{~mL}$ solution $(5 \mathrm{~mL}$ borate buffer +5 $\mathrm{mL}$ pure water) following the same procedure (extract 2). Both extracts $(1+2)$ were combined and $5 \mathrm{~mL}$ of FMOC- $\mathrm{Cl}\left(10 \mathrm{~g} \mathrm{~L}^{-1}\right)$ and $5 \mathrm{~mL} \mathrm{ACN}$ were added. The samples were then derivatized for 1 hour at room temperature in the dark while stirring. The samples were then

171 left for 2 hours at room temperature in the dark without stirring before to remove the excess

172 FMOC-Cl by liquid-liquid extraction (LLE) with diethyl ether $(7.5 \mathrm{~mL})$, through vortex

173 agitation for 1 minute. This LLE was repeated twice and this extraction allow to optimize the analyse, thereby keeping the ionization chamber of the mass spectrometer clean. The aqueous fraction was collected and adjusted to $250 \mathrm{~mL}$ with pure water. The $\mathrm{pH}$ was adjusted to 3 with formic acid before the SPE procedure.

SPE was carried out using 6 mL Chromabond® XLB cartridges (Macherey-Nägel, France) containing $200 \mathrm{mg}$ of the phase and an autotrace ${ }^{\circledR} 280$ (ThermoScientific, France). The cartridge was first conditioned by successive addition of $5 \mathrm{~mL} \mathrm{MeOH}, 5 \mathrm{~mL}$ pure water and 5 $\mathrm{mL}$ formic acid solution $(\mathrm{pH} 3)$ at $5 \mathrm{~mL} \mathrm{~min}^{-1}$, then the $250 \mathrm{~mL}$ of the sample solution was deposited at $10 \mathrm{~mL} \mathrm{~min}{ }^{-1}$. The cartridge was dried under nitrogen for 20 minutes and the elution was carried out with $2 \times 2 \mathrm{~mL}$ of $\mathrm{MeOH}$ containing $1 \%$ formic acid at $5 \mathrm{~mL} \mathrm{~min}^{-1}$.

\subsection{Earthworm extraction}

Earthworms (1 g) were cut into small pieces using Inox scissors and inserted into $15 \mathrm{~mL}$ $\mathrm{mg} \mathrm{L}^{-1}$ was added and vortexed. The earthworms were then digested for 20 minutes at $50^{\circ} \mathrm{C}$

188 with $2 \mathrm{~mL} \mathrm{KOH}$ solution $(\mathrm{pH} \mathrm{12)}$ in order to solubilize all proteins and other molecules [37].

189 After centrifugation, the supernatant was derivatized in a plastic flask with $5 \mathrm{~mL}$ borate $(50 \mathrm{~g}$ 
pure water and adjusted to $\mathrm{pH} 3$ with formic acid, followed by centrifugation for 15 minutes

193 at $1,252 \mathrm{~g}$. The supernatant was extracted by LLE with diethyl ether $(10 \mathrm{~mL})$ through vortex

194 agitation for 1 minute. This LLE was repeated twice. The aqueous fraction was collected and 195 adjusted to $250 \mathrm{~mL}$ with pure water before SPE. The SPE procedure was identical to that used 196 for soil.

\subsection{LC/MS/MS Analysis}

A Thermo Scientific TSQ Quantum Access Triple Quadrupole Mass Spectrometer coupled with a Surveyor pump and an Accela autosampler operating in heated positive electrospray ionization mode (HESI+) was used. The sampler is equipped with a $20 \mu \mathrm{L}$ injection loop and the samples were kept at a temperature of $15^{\circ} \mathrm{C}$. The analysis was performed on a Nucleodur $\mathrm{C}_{18}$ Pyramid column $(150 \mathrm{~mm} \times 3 \mathrm{~mm}, 3 \mu \mathrm{m})$ at $25^{\circ} \mathrm{C}$. Samples were analyzed using a mobile phase water/ACN both containing $0.1 \%$ formic acid, at a flow rate of $0.5 \mathrm{~mL} \mathrm{~min}{ }^{-1}$. The composition of the mobile phase was kept at 60:40 for $2 \mathrm{~min}$, then held to 5:95 (v/v) in 8 min (2 min hold), then 60:40 (v/v) in 2 min for $3 \mathrm{~min}$.

Detection and quantitation of GLY, GLU and AMPA were performed using multiple reactions monitoring (MRM). The ion source was operated in positive ion mode with a spray voltage of $4,500 \mathrm{~V}$ and a vaporizer and capillary temperature of $300^{\circ} \mathrm{C}$ each. Nitrogen was used for sheath and auxiliary gas pressure (20 and 10 arbitrary units) while argon was used for collision pressure (1.5 arbitrary unit). Two precursor product ion transitions for each analyte

212 and each internal standard were used for quantitation. $Q$ for quantification transition, $q$ for 213 qualification transition and Ec for collision energy (V)) were used from precursor ion as 214 follows: glyphosate $(Q) \mathrm{m} / \mathrm{z}$ 392/179 (42 V) and $(q) \mathrm{m} / \mathrm{z}$ 392/88 (18V); AMPA $(Q) \mathrm{m} / \mathrm{z}$ 334/179 (23 V) and (q) $\mathrm{m} / \mathrm{z}, 334 / 156(69 \mathrm{~V})$; glufosinate $(Q) \mathrm{m} / \mathrm{z}, 404 / 182(13 \mathrm{~V})$ and $(q) \mathrm{m} / \mathrm{z}$ 
$m / z$ 376/179 (25 V) and $m / z(q) 376 / 156(5 \mathrm{~V})$. Data were acquired and processed using

218 Excalibur software.

219 Both ion transitions had mean accuracies between 70 and $120 \%$ and a precision of $20 \%$ 220 relative standard deviation (RSD), based on at least five replicates.

\subsection{Calibration, limits of detection and quantification}

223 For soils, a calibration step was performed by obtaining curves with pure water spiked with increasing amounts of GLY, GLU and AMPA. Linearity of the method was evaluated analyzing six standard solutions by triplicate in the range $0.010-1.0 \mathrm{mg} \mathrm{L}^{-1}$. The concentration of the internal standards was the same as those used for soil sample extraction. APPA was used for the calibration while AMPPA was used to evaluate the effectiveness of the derivatization step. . The procedure was the same as for derivatization of the soil extract. For earthworms, a calibration step was carried out on the matrix by spiking blank small cut pieces of earthworm with increasing concentrations of the three analytes, at six concentration levels by triplicate in the range $0.010-1.0 \mathrm{mg} \mathrm{L}^{-1}$. APPA and AMPPA were used as IS to evaluate 232 the calibration and extraction/derivatization steps, respectively. The blank earthworms were 233 analysed in the laboratory to ensure the absence of pesticide contamination. The spiked 234 earthworms were processed using the same procedure as the experimental samples.

235 The limits of quantification (LOQ) and detection (LOD) for soil and earthworms were 236 determined by the signal to noise ratio (S/N) with: $\mathrm{S} / \mathrm{N}=10$ for $\mathrm{LOQ}$ and $\mathrm{S} / \mathrm{N}=3$ for LOD.

237 For soil samples, the repeatability was determined by analyzing, on the same day, five sub238 samples $(15 \mathrm{~g})$ from a sample of soil spiked with $40 \mu \mathrm{L}$ of a mixture of herbicides at $10 \mathrm{mg} \mathrm{L}^{-}$ $239{ }^{1}$ each, using the same analytical method. The reproducibility was determined by analyzing 240 three sub-samples (15 g) from the same sample of soil used to determine the repeatability. 241 The sub-samples were analyzed using the same analytical method with a one-week interval 
between analyses. The composition and the characteristics of soil sample used to validate the

243 method were soil texture (sand (18\%); silt (39\%) and clay (43\%)), $\mathrm{pH}(\mathrm{H} 2 \mathrm{O})$ of 8.11 and a

244 value of $4 \%$ for organic C.

245 For earthworms, the repeatability was determined by analyzing five blank earthworm 246 replicates with a mixture of GLY, GLU and AMPA at $0.05 \mathrm{mg} \mathrm{L}^{-1}$ and the reproducibility was 247 determined by analyzing three replicates.

\section{Results and Discussion}

\subsection{Column selection}

GLY, GLU, AMPA and both IS were separated on a Nucleodur $\mathrm{C}_{18}$ pyramid $(150 \mathrm{~mm} \times 3$ mm diameter, $3 \mu \mathrm{m}$ particle size) column. The retention times (RT) with the conditions used as described in the Materials and Methods section were $6.45 \mathrm{~min}$ for GLU, 7.57 min for GLY, 8.79 min for AMPA, 9.74 min for APPA and 10.35 min for AMPPA.

Another column, the Nucleoshell $\mathrm{RP}_{18}(100 \mathrm{~mm} \times 2 \mathrm{~mm}$ diameter, $2.7 \mu \mathrm{m}$ particle size $)$ was tested, as lower dimensions were expected to increase the resolution and improve the 258 limits of detection. Macherey-Nägel suggests this column as a good solution for GLY, GLU and AMPA separation (MN Appl. No.126110). The resolution was, as expected, better than that obtained using the Nucleodur Pyramid and the S/N ratio was higher. However, the use of

261 ammonium acetate buffer at $50 \mathrm{mmol} \mathrm{L}^{-1}$ led to an increase in pressure above 500 bars which, 262 due to standard HPLC pump capacities, required frequent cleaning of the stationary phase and 263 the frits. In addition, the retention time of all the analytes was very short (less than 1 minute) 264 and not consistent with the Macherey-Nägel application note under the same conditions (same 265 flow rate and gradient). 
Due to these limitations, even if the Nucleoshell allowed better resolution and lower detection limits, it was decided to perform all analyses with the Nucleodur Pyramid column.

\subsection{Choice of internal standards (IS)}

Previous analytical methods developed to measure GLY, GLU and AMPA in diverse matrices [[32], [34], [38], [39]] used isotope-labeled internal standards (i.e. (1,2$\left.{ }^{13} \mathrm{C}^{15} \mathrm{~N}\right)$ Glyphosate, $\left(\mathrm{D}_{2}{ }^{13} \mathrm{C}^{15} \mathrm{~N}\right) \mathrm{AMPA}, \mathrm{D}_{3}$ glufosinate $)$ for efficient quantification and derivatization. However, even if these IS appeared to be performing, problems of sensitivity and stability over time were encountered. For this reason, it was decided to select other internal standards such as APPA and AMPPA. These two molecules have a chemical structure very close to the herbicides, are not used in agriculture, are very stable over time and allow sensitive detection (Figure 3).

\subsection{Extraction optimization}

280 Previously, soil was generally extracted by stirring in diverse buffered or basic aqueous 281 solutions such as: $40 \mathrm{mM}$ Na-tetraborate [40], $0.1 \mathrm{M} \mathrm{KH}_{2} \mathrm{PO}_{4}$ [41], water [[31], [42]], $0.6 \mathrm{M}$ $282 \mathrm{KOH}$ [[7], [43]] or mixture of sodium phosphate $0.03 \mathrm{M}$ and trisodium citrate $0.01 \mathrm{M}$ [44]. 283 These methods used stirring for different lengths of time, generally at room temperature, and 284 centrifugation to separate the soil from the extracting solution. In this context, different 285 extraction solutions were tested in the present study (borate buffer ( $\mathrm{pH} \mathrm{10),} \mathrm{water} \mathrm{(} \mathrm{pH}$ 6),

$286 \mathrm{KOH}(\mathrm{pH} 13)$ and $\left.\mathrm{HNO}_{3}(\mathrm{pH} 3)\right)$, using $15 \mathrm{~g}$ of soil spiked with $5 \mu \mathrm{g}$ of AMPA, GLU and 287 GLY, and $2 \mu \mathrm{g}$ of each IS. The protocol described in figure 1 was applied without the SPE 288 step. Results are presented in figure 4a and show the best recoveries were obtained with 289 borate buffer (51\% for AMPA, $53 \%$ for GLY and $55 \%$ for GLU). Also of note was that the 290 recoveries obtained with water were significantly better than those previously obtained by 
Druart et al. [31] for GLY (37 \%), equivalent for AMPA (38\%) and lower for GLU (40\%).

292 The composition of the soil and particularly its organic matter or clay content could explain 293 these differences [[40], [45]]. Moreover, with borate buffer for extraction, it was not 294 necessary to adjust the $\mathrm{pH}$ to achieve the derivatization phase [30] unlike with other solvents. 295 Indeed, if $\mathrm{KOH}$ is used, a supplementary step to adjust the $\mathrm{pH}$ from 13 to 9 before 296 derivatization is necessary. Using borate buffer this step is not required and the extract is in 297 the same solvent as that used for derivatization.

298 The extraction time was optimized using borate as the extraction solvent, and it was found 299 that an increase in the extraction time above $1 \mathrm{~h}$ did not increase recoveries (Figure $4 \mathrm{~b}$ ). In 300 contrast, recoveries decreased, probably due to re-adsorption of the herbicides on soil 301 particles during longer stirring times.

\subsection{SPE Optimization}

HLB cartridges are commonly used for a SPE pre-concentration step of FMOC-glyphosate, FMOC-glufosinate and FMOC-AMPA [[29], [34], [45]]. The SPE procedure used in this study was derived from that of Ghanem et al. [29] but the conditioning step was modified by replacing the phosphate buffer $(\mathrm{pH} 3)$ with formic acid at $\mathrm{pH} 3$ and the flow rate of the sample was reduced to $10 \mathrm{~mL} \mathrm{~min}{ }^{-1}$ to ensure better adsorption of the molecules onto the phase.

309 Differences between phosphate buffer and formic acid were not significant and formic acid 310 was used to make the SPE protocol easier. Elution with $\mathrm{MeOH}$ gave recoveries of $59 \%$ for 311 AMPA, $63 \%$ for GLY and $61 \%$ for GLU. In order to increase these recoveries, different 312 solvents were tested. Recoveries obtained with these solvents are presented in figure 5. 313 Acidification of $\mathrm{MeOH}$ with $1 \%$ formic acid increased the recoveries. Thus, $2 \times 2 \mathrm{~mL} \mathrm{MeOH}$ 314 (1 \% formic acid) was chosen as the elution solution to pre-concentrate the soil and 315 earthworm samples. 


\subsection{Calibration}

318 The LC/MS/MS method was internally calibrated to quantify GLY, GLU and AMPA. For 319 soil samples, a good linearity was observed for the responses with correlation coefficients 320 showing values of 0.996 for GLY, 0.992 for GLU and 0.989 for AMPA, using the linear 321 regression model. The deviation from linearity in responses for the earthworm samples was 322 probably due to a matrix effect. Therefore, we used a quadratic regression model to minimize this deviation. The correlation coefficients were then 0.982 for GLY, 0.976 for GLU and 0.985 for AMPA. For the earthworm samples, the calibration step was carried out in the matrix unlike soil samples. Indeed, there was no significant difference between the angular coefficients of the calibration curve in solution and in matrix.

\subsection{Method performance criteria}

The method performance criteria were evaluated for soil and earthworms (table 1). To our knowledge, no previous scientific studies investigated the quantification of the compounds of 331 interest in earthworms.

332 Several previous studies proposed methods for determining GLY and AMPA in soils, and only a few of them included GLU [[34], [4]]. Most of these reported higher LOQ, with values

$334 \geq 0.050 \mu \mathrm{g} \mathrm{g}^{-1}$ for GLY [[34], [43], [45], [46]] (table 2). However, Rampazzo Todorovic et al. 335 [40] showed that all criteria including LOQ were highly dependent on the soil type, as they 336 found that the LOQ for GLY ranged from 0.014 to $0.14 \mu \mathrm{g} \mathrm{g}^{-1}$ in their tested soils. The 337 present study led to comparable LOQ for GLY, GLU and AMPA, with the order GLY > 338 AMPA > GLU. The same order (or equivalence between compounds) was also found by most 339 other authors. In terms of repeatability and reproducibility, the present study is in the same 340 range or better than most of the other studies. The main differences with other reports were 
the quantity of soil extracted, which was $15 \mathrm{~g}$ in our case but $5 \mathrm{~g}$ or less in most other studies

342 (except Sun et al., 2017 [44], which used $10 \mathrm{~g}$ ).

\section{Application to environmental samples}

345 The developed method was applied to analyze six soil samples and six earthworms collected

346 in the same soils. In parallel, blank samples were analyzed to confirm the absence of cross

347 contamination. As observed in figure 6, the analytes and internal standards were clearly

348 defined and, due to the SPE purification, the noise signal remained low.

349 GLU was rarely detected, and was only quantified in one soil sample and observed in trace 350 amounts in another one (table 3). However, GLY was found at quantifiable levels in all the 351 soil samples, and AMPA was detected in all except one. The concentrations ranged between 3520.18 and $0.069 \mu \mathrm{g} \mathrm{g}^{-1}$ for GLY, ie largely above the LOQ. In contrast, for AMPA the concentrations were closer to the LOQ and ranged from 0.073 to $0.025 \mu \mathrm{g} \mathrm{g}^{-1}$. All the measurements were confirmed by the qualification transition, with a deviation of the $\mathrm{Q}_{1} / \mathrm{Q}_{3}$ ratio within the accepted tolerance (in all case $<20 \%$ ).

Comparing the observed concentrations, GLY and its AMPA metabolite appeared to be far below the concentrations observed in the US and Argentina for example [[9], [47], [48]], where glyphosate usage rates and occurrence are higher. However, they were within the range 359 usually observed in Europe, particularly in cereal crops [[7], [42], [46]]. In soils, the AMPA 360 concentration was commonly described as higher than that of GLY [[9], [42], [48]] but it was 361 not systematically the case and some soil properties were found to favor equivalent 362 concentrations, or even GLY > AMPA [46].

363 In earthworms, GLY was only quantified in two of the field-collected earthworms, even if 364 GLU, GLY and AMPA were regularly detected below LOQ. This relatively rare measurement 365 could be associated with low GLY bioavailability in soil [49]. Furthermore, GLY is 
considered to show a low potential for bioconcentration, with a Bioconcentration Factor (BCF) for fish calculated at 0.5 [5]. The two measurements in the soil samples and earthworms in this study were used to calculate a BCF of $0.251 / 0.179=1.4$ and $0.230 / 0.130=$ 1.8, respectively. Both are within the range of 1.4-5.9, found by Contardo-Jara et al. [50] for Lumbriculus variegatus in water.

\section{Conclusion}

373 A sensitive and selective analytical method was developed to quantify GLY, AMPA and GLU in soils and earthworms, enabling the effective analyses of these compounds in field-collected samples. After the extraction step, the extracts were derivatized with FMOC-Cl and purified on SPE cartridges before internal standard quantification using LC/MS/MS in HESI+ mode.

The extraction and purification methods were optimized. For extraction, the best recoveries were obtained with borate buffer and reached a maximum after $1 \mathrm{~h}$ incubation. In order to increase the performance of the SPE, various solvents were tested and the acidification of $\mathrm{MeOH}$ with $1 \%$ formic acid increased the recoveries, so elution with $2 \times 2 \mathrm{~mL} \mathrm{MeOH}(1 \%$

381 formic acid) was selected to pre-concentrate the soil and earthworm samples.

382 The method developed achieves a good linearity for the calibration responses in soil, and 383 high correlation coefficients were observed for earthworm samples using a quadratic 384 regression model. The LOD and LOQ values measured with this method were among the 385 lowest range of values reported for soil in the literature. The method also allowed sensitive 386 detection and quantification in a complex animal matrix such as earthworms, with a LOD of $3870.070 \mu \mathrm{g} \mathrm{g} \mathrm{g}^{-1}, 0.065 \mu \mathrm{g} \mathrm{g}^{-1}$ and $0.040 \mu \mathrm{g} \mathrm{g}^{-1}$ for GLY, AMPA and GLU, respectively. 388 Accordingly, the LOQ were $0.23 \mu \mathrm{g} \mathrm{g}^{-1}, 0.20 \mu \mathrm{g} \mathrm{g}^{-1}$ and $0.12 \mu \mathrm{g} \mathrm{g}^{-1}$ in earthworm samples for GLY, AMPA and GLU, respectively. 
The method was successfully applied to analyse residues in natural soils and earthworms collected in cereal crop fields, with quantification of the three compounds in these field samples. All measurements were confirmed by the use of two MS/MS transitions.

This optimized method for analyzing GLY, AMPA and GLU in soil and animal matrices

394 represents a promising analytical tool with regards to the current needs for monitoring commonly used pesticides in the environment.

\section{Acknowledgements}

This study was carried out within the framework of the "PING" research project, funded by the Métaprogramme INRAE SMaCH Call 2017. The study also benefited from the samples collected during the "RESCAPE" research project, led by the Ministry for Agriculture and Food and the Ministry for an Ecological and Solidary Transition, with the financial support of the French Biodiversity Agency on "Resistance and Pesticides", with the fees for diffuse pollution coming from the Ecophyto Plan through the national agency ONEMA. We thank the ZAPVS for help accessing the field plots.

\section{References}

[1] Z. Kissane, J.M. Shephard The rise of glyphosate and new opportunities for biosentinel early-warning studies. Conservation Biology, 31(6) (2017), pp. 1293-1300. https://doi.org/10.1111/cobi.12955

[2] A. Székács, B. Darvas Re-registration Challenges of Glyphosate in the European Union. Front. Environ. Sci., 6 (2018), pp. 1-35. doi: 10.3389/fenvs.2018.00078

[3] E. Mallat, D. Barceló Analysis and degradation study of glyphosate and of aminomethylphosphonic acid in natural waters by means of polymeric and ion-exchange solid-phase extraction columns followed by ion chromatography-post-column derivatization with fluorescence detection. J. Chromatogr. A, 823 (1998), pp. 129-136.

[4] C. Accinelli, C. Screpanti, A. Vicari, P. Catizone Influence of insecticidal toxins from Bacillus thuringiensis subsp. kurstaki on the degradation of glyphosate and glufosinateammonium in soil samples. Agric. Ecosyst. Environ., 103 (2004), pp. 497-507. 
[5] PPDB (Pesticide Properties DataBase) (2020)

[6] J. Dollinger, C. Dages, M. Voltz Glyphosate sorption to soils and sediments predicted by pedotransfer functions. Environ. Chem. Lett., 13 (2015), pp. 293-307.

[7] V. Silva, L. Montanarella, A. Jones, O. Fernández-Ugalde, H.G.J. Mol, C.J. Ritsema, V. Geissen Distribution of glyphosate and aminomethylphosphonic acid (AMPA) in agricultural topsoils of the European Union., 621 (2018), pp. 1352-1359. https://doi.org/10.1016/j.scitotenv.2017.10.093

[8] M.G.D. Sousa, A.C. da Silva, R.D. Araujo, R.M. Rigotto Evaluation of the atmospheric contamination level for the use of herbicide glyphosate in the northeast region of Brazil. Environ. Monit. Assess., 191 (2019), pp. 11.

[9] E.A. Scribner, W.A. Battaglin, R.J. Gilliom, M.T. Meyer Concentrations of glyphosate, its degradation product, aminomethylphosphonic acid, and glufosinate in ground- and surfacewater, rainfall, and soil samples collected in the United States, 2001-06. U.S. Geological Survey Scientific Investigations Report 2007-5122, 111 p.

[10] C. Druart, M. Millet, R. Schleifer, O. Delhomme, A. de Vaufleury Glyphosate and glufosinate-based herbicides: fate in soil, transfer to and effects on land snails. J. Soils Sediments, 11 (2011a), pp. 1373-1384.

[11] R.A. King, I.P. Vaughan, J.R. Bell, D.A. Bohan, W.O.C. Symondson Prey choice by carabid beetles feeding on an earthworm community analysed using species- and lineagespecific PCR primers. Mol. Ecol., 19 (2010), pp. 1721-1732. https://doi.org/10.1111/j.1365-294X.2010.04602.X

[12] T. Liu, X. Chen, X. Gong, I.M. Lubbers, Y. Jiang, W. Feng, X. Li, J.K. Whalen, M. Bonkowski, B.S. Griffiths, F. Hu, M. Liu Earthworms Coordinate Soil Biota to Improve Multiple Ecosystem Functions. Curr. Biol., 29 (2019), pp. 3420-3429. https://doi.org/10.1016/j.cub.2019.08.045

[13] J.W. van Groenigen, I.M. Lubbers, H.M.J. Vos, G.G. Brown, G.B. De Deyn, K.J. van Groenigen Earthworms increase plant production: a meta-analysis. Sci. Rep., 4 (2014), p. 6365. https://doi.org/10.1038/srep06365

[14] S. Yasmin, D. D'Souza Effect of pesticides on the reproductive output of Eisenia fetida. Bull. Environ. Contam. Toxicol., 79 (2007), pp. 529-532.

[15] F.V. Correia, J.C. Moreira Effects of glyphosate and 2,4-D on earthworms (Eisenia foetida) in laboratory tests. Bull. Environ. Contam. Toxicol., 85 (2010), pp. 264-268.

[16] M.T. Rose, T.R. Cavagnaro,C.A. Scanlan, T.J. Rose, T. Vancov, S. Kimber, I.R. Kennedy, R.S. Kookana, L. Van Zwieten Impact of Herbicides on Soil Biology and Function. In: Sparks, D.L. (Ed.), Advances in Agronomy, 136 (2016). Elsevier Academic Press Inc, San Diego, pp. 133-220.

[17] J.P.K. Gill, N. Sethi, A. Mohan, S. Datta, M. Girdhar Glyphosate toxicity for animals. Environ. Chem. Lett., 16 (2018), pp. 401-426.

[18] J.G. Zaller, F. Heigl, L. Ruess, A. Grabmaier Glyphosate herbicide affects belowground interactions between earthworms and symbiotic mycorrhizal fungi in a model ecosystem. Sci. Rep., 4 (2014), p. 5634.

[19] A.L. Valle, F.C.C. Mello, R.P. Alves-Balvedi, L.P. Rodrigues, L.R. Goulart Glyphosate detection: methods, needs and challenges. Environ. Chem. Lett., 17 (2019), pp. 291-317. https://doi.org/10.1007/s10311-018-0789-5

[20] V. Subramaniam, P.E. Hoggard Metal complexes of glyphosate. J. Agric. Food Chem., 36 (1988), pp. 1326-1329.

[21] A. Sundaram, K.M.S. Sundaram Solubility products of six metal-glyphosate complexes in water and forestry soils, and their influence on glyphosate toxicity to plants. J. Environ. Sci. Health B, 32 (1997) 583-598. 
[22] C.D. Stalikas, C.N. Konidari Analytical methods to determine phosphonic and amino acid group-containing pesticides. J. Chromatogr. A, 907 (2001), pp. 1-19.

[23] A. Royer, S. Beguin, J.C. Tabet, S. Hulot, M.A. Reding, P.Y. Communal Determination of Glyphosate and Aminomethylphosphonic Acid Residues in Water by Gas Chromatography with Tandem Mass Spectrometry after Exchange Ion Resin Purification and Derivatization. Application on Vegetable Matrixes. Anal. Chem., 72 (2000), pp. 38263832.

[24] J.Y. Hu, C.L. Chen, J.Z. Li A Simple Method for the Determination of Glyphosate Residues in Soil by Capillary Gas Chromatography with Nitrogen Phosphorus. J. Anal. Chem., 63 (2008), pp. 371-375.

[25] Y. Zhu, F. Zhang, C. Tong, W. Liu Determination of glyphosate by ion chromatography. J. Chromatogr. A, 850 (1999), pp. 297-301.

[26] H. Guo, L.S. Riter, C.E. Wujcik, D.W. Armstrong Direct and sensitive determination of glyphosate and aminomethylphosphonic acid in environmental water samples by high performance liquid chromatography coupled to electrospray tandem mass spectrometry. J. Chromatogr. A, 1443 (2016), pp. 93-100.

[27] Z.L. Chen, W.X. He, M. Beer, M. Megharaj, R. Naidu Speciation of glyphosate, phosphate and aminomethylphosphonic acid in soil extracts by ion chromatography with inductively coupled plasma mass spectrometry with an octopole reaction system. Talanta, 78 (2009), pp. 852-856.

[28] B. Le Bot, K. Colliaux, D. Pelle, C. Briens, R. Seux, M. Clement Optimization and performance evaluation of the analysis of glyphosate and AMPA in water by HPLC with fluorescence detection. Chromatographia, 56 (2002), pp. 161-164.

[29] A. Ghanem, P. Bados, L. Kerhoas, J. Dubroca, J. Einhorn Glyphosate and AMPA Analysis in Sewage Sludge by LC-ESI-MS/MS after FMOC Derivatization on Strong Anion-Exchange Resin as Solid Support. Anal. Chem., 79 (2007), pp. 3794-3801.

[30] T.V. Nedelkoska, G.K.C. Low High-performance liquid chromatographic determination of glyphosate in water and plant material after pre-column derivatisation with 9fluorenylmethyl chloroformate. Anal. Chim. Acta, 511 (2004), pp. 145-153.

[31] C. Druart, O. Delhomme, A. de Vaufleury, E. Ntcho, M. Millet Optimization of extraction procedure and chromatographic separation of glyphosate, glufosinate and aminomethylphosphonic acid in soil. Anal. Bioanal. Chem., 399 (2011b), pp. 1725-1732. https://doi.org/10.1007/s00216-010-4468-Z

[32] Z.H. Guo, Q. Cai, Z. Yang Determination of glyphosate and phosphate in water by ion chromatography_inductively coupled plasma mass spectrometry detection. J. Chromatogr. A, 1100 (2005), pp. 160-167.

[33] T. Arkan, I. Molnar-Perl The role of derivatization techniques in the analysis of glyphosate and aminomethyl-phosphonic acid by chromatography. Microchem. J., 121 (2015), pp. 99-106.

[34] M. Ibanez, O.J. Pozo, J.V. Sancho, F.J. Lopez, F. Hernandez Residue determination of glyphosate, glufosinate and aminomethylphosphonic acid in water and soil samples by liquid chromatography coupled to electrospray tandem mass spectrometry. J. Chromatogr. A, 1081 (2005), pp. 145-155. https://doi.org/10.1016/j.chroma.2005.05.041[35] C. Pelosi, L. Toutous, F. Chiron, F. Dubs, M. Hedde, A. Muratet Reduction of pesticide use can increase earthworm populations in wheat crops in a European temperate region. Agric. Ecosys. Environ., 181(1) (2013), pp. 223-30.

[36] V. Bretagnolle, E. Berthet, N.Gross, B. Gauffre, C. Plumejeaud, S. Houte, I. Badenhausser, K. Monceau, F. Allier F, P. Monestiez, S. Gaba Towards sustainable and multifunctional agriculture in farmland landscapes: Lessons from the integrative approach of a French LTSER platform. Sci. Tot. Environ., 627 (2018), pp. 822-834. 
https://doi.org/10.1016/j.scitotenv.2018.01.142

[37] P. Byambas, A. Lemtiri, J.L. Hornick, T. Bengone Ndong, F. Francis Rôles et caractéristiques morphologiques $\mathrm{du}$ ver de terre Eudrilus eugeniae (synthèse bibliographique). Biotechnologie, Agronomie, société et Environnement, volume 21 (2017). https://doi.org/10.25518/1780-4507.16259

[38] N. Chamkasem, T. Harmon Direct determination of glyphosate, glufosinate, and AMPA in soybean and corn by liquid chromatography/tandem mass spectrometry. Anal. Bioanal. Chem., 408 (2016), pp. 4995-5004. https://doi.org/ 0.1007/s00216-016-9597-6

[39] C. Schrübbers, M. Masís-Mora, E. Carazo Rojas, B.E. Valverde, J.H. Christensen, N. Cedergreen Analysis of glyphosate and aminomethylphosphonic acid in leaves from Coffea arabica using high performance liquid chromatography with quadrupole mass spectrometry detection. Talanta,146 (2016), pp. 609-620.

[40] G. Rampazzo Todorovic, A. Mentler, M. Popp, S. Hann, G. Köllensperger, N. Rampazzo, W.E.H. Blum Determination of Glyphosate and AMPA in Three Representative Agricultural Austrian Soils with a HPLC-MS/MS Method. Soil and Sediment Contamination. An International Journal, 22 (2013), pp. 332-350.

https://doi.org/10.1080/15320383.2013.726296

[41] C.G. Soracco, R. Villarreal, L.A. Lozano, S. Vittori, E.S. Melani, D.J.G. Marino Glyphosate dynamics in a soil under conventional and no-till systems duringa soybean growing season. Geoderma, 323 (2018), pp. 13-21. https://doi.org/10.1016/j.geoderma.2018.02.041

[42] T. Erban, M. Stehlik, B. Sopko, M. Markovic, M. Seifrtova, T. Halesova, P. Kovaricek The different behaviors of glyphosate and AMPA in compost-amended soil. Chemosphere, 207 (2018), pp. 78-83. https://doi.org/10.1016/j.chemosphere.2018.05.004

[43] C.P.M. Bento, X.M. Yang, G. Gort, S. Xue, R. van Dam, P. Zomer, H.G.J. Mol, C.J. Ritsema, V. Geissen Persistence of glyphosate and aminomethylphosphonic acid in loess soil under different combinations of temperature, soil moisture and light/darkness. Sci. Tot. Environ., 572 (2016), pp. 301-311. http://dx.doi.org/10.1016/j.scitotenv.2016.07.215

[44] L.S. Sun, D.Y. Kong, W.D. Gu, X.Y. Guo, W.Q. Tao, Z.J. Shan, Y. Wang, N. Wang Determination of glyphosate in soil/sludge by high performance liquid chromatography. J. Chromatogr. A, 1502 (2017), pp. 8-13. http://dx.doi.org/10.1016/j.chroma.2017.04.018

[45] A.M. Botero-Coy, M. Ibanez, J.V. Sancho, F. Hernandez Improvements in the analytical methodology for the residue determination of the herbicide glyphosate in soils by liquid chromatography coupled to mass spectrometry. J. Chromatogr. A, 1292 (2013), pp. 132141. http://dx.doi.org/10.1016/j.chroma.2012.12.007

[46] H. Karasali, G. Pavlidis, A. Marouso Poulou Investigation of the presence of glyphosate and its major metabolite AMPA in Greek soils. Environ. Sci. Pollut. Res., 26 (2019), pp. 36308-36321. https://doi.org/10.1007/s11356-019-06523-X

[47] L. Lupi, K.S.B. Miglioranza, V.C. Aparicio, D. Marino, F. Bedmar, D.A. Wunderli Occurrence of glyphosate and AMPA in an agricultural watershed from the southeastern region of Argentina. Sci. Tot. Environ., 536 (2015), pp. 687-694.

http://dx.doi.org/10.1016/j.scitotenv.2015.07.090

[48] J.E. Primost, D.J.G. Marino, V.C. Aparicio, J.L. Costa, P. Carriquiborde Glyphosate and AMPA, "pseudo-persistent" pollutants under realworld agricultural management practices in the Mesopotamic Pampas agroecosystem, Argentina. Environ. Pollut., 229 (2017), pp. 771-779. http://dx.doi.org/10.1016/j.envpol.2017.06.006

[49] L. Mamy, E. Barriuso Glyphosate adsorption in soils compared to herbicides replaced with the introduction of glyphosate resistant crops. Chemosphere, 61 (2005), pp. 844-855. https://doi.org/10.1016/j.chemosphere.2005.04.051 
570

571

572

573

574

575

576

577

578

579

[50] V. Contardo-Jara, E. Klingelmann, C. Wiegand Bioaccumulation of glyphosate and its formulation Roundup Ultra in Lumbriculus variegatus and its effects on biotransformation and antioxidant enzymes. Environ. Pollut., 157 (2009), pp. 57-63.

https://doi.org/10.1016/j.envpol.2008.07.027 
Table 1: Performance criteria of the method developed for soil and earthworms: limits of detection (LOD) and quantification (LOQ), repeatability and reproducibility.

\begin{tabular}{llccc}
\hline & & Glyphosate & AMPA & Glufosinate \\
\hline Soil & LOD $\left(\mu \mathrm{g} \mathrm{g}^{-1}\right)$ & 0.009 & 0.007 & 0.006 \\
$(\mathrm{~m}=15 \mathrm{~g})$ & LOQ $\left(\mu \mathrm{g} \mathrm{g}^{-1}\right)$ & 0.030 & 0.025 & 0.020 \\
& repeatability* $(\%)$ & 5.0 & 7.4 & 7.0 \\
& reproducibility* $(\%)$ & 5.7 & 7.9 & 6.5 \\
\hline Earthworm & LOD $\left(\mu \mathrm{g} \mathrm{g}^{-1}\right)$ & 0.070 & 0.065 & 0.040 \\
$(\mathrm{~m}=1 \mathrm{~g})$ & LOQ $\left(\mu \mathrm{g} \mathrm{g}^{-1}\right)$ & 0.23 & 0.20 & 0.12 \\
& repeatability** $(\%)$ & 7.8 & 8.3 & 7.2 \\
& reproducibility** $(\%)$ & 8.4 & 9.2 & 8.0 \\
\hline
\end{tabular}

$*$ : concentration of compounds in the soil sample (GLY $=0.10 \mathrm{mg} \mathrm{L}^{-1}, \mathrm{AMPA}=0.075 \mathrm{mg} \mathrm{L}^{-1}$ and GLU $=0.050$ $\left.\mathrm{mg} \mathrm{L} \mathrm{L}^{-1}\right)$

**: mixture of GLY, GLU and AMPA at $0.050 \mathrm{mg} \mathrm{L}^{-1}$ 
Table 2 : comparison of the method performance with those in the literature

\begin{tabular}{lcccc} 
& $\mathrm{LOD}\left(\mu \mathrm{g} \mathrm{g}^{-1}\right)$ & $\mathrm{LOQ}\left(\mu \mathrm{g} \mathrm{g}^{-1}\right)$ & Mass soil $(\mathrm{g})$ & reference \\
\hline Glyphosate & 0.020 & 0.050 & 2 & {$[7]$} \\
& 0.010 & $\mathrm{nd}$ & 5 & {$[24]$} \\
& 0.005 & 0.050 & 5 & {$[34]$} \\
& $0.004-0.047$ & $0.014-0.023$ & 3 & {$[40]$} \\
& 0.010 & 0.040 & 10 & {$[44]$} \\
& 0.020 & 0.050 & 2 & {$[45]$} \\
AMPA & nd & 0.010 & 5 & {$[46]$} \\
& 0.009 & 0.030 & 15 & This work \\
\hline 0.030 & 0.050 & 2 & {$[7]$} \\
& 0.005 & 0.050 & 5 & {$[34]$} \\
& $0.025-0.12$ & $0.084-0.089$ & 3 & {$[40]$} \\
& 0.010 & 0.030 & 2 & {$[45]$} \\
Glufosinate & nd & 0.010 & 5 & [46] \\
& 0.007 & 0.025 & 15 & This Work \\
\hline 0.005 & 0.050 & 5 & [34] \\
& 0.006 & 0.020 & 15 & This work
\end{tabular}

nd : not determined

Table 3: Concentrations measured in the six soil and earthworm samples

\begin{tabular}{|c|c|c|c|c|c|}
\hline \multicolumn{3}{|c|}{ Soil $\left(\mu \mathrm{g} \mathrm{g}^{-1}\right)$} & \multicolumn{3}{|c|}{ Earthworms $\left(\mu \mathrm{g} \mathrm{g}^{-1}\right)$} \\
\hline Glyphosate & AMPA & Glufosinate & Glyphosate & AMPA & Glufosinate \\
\hline 0.069 & 0.070 & 0.041 & $<$ LOQ & $<$ LOQ & nd \\
\hline 0.093 & 0.025 & $\mathrm{nd}^{*}$ & $<\mathrm{LOQ}$ & $<\mathrm{LOQ}$ & nd \\
\hline 0.095 & nd & nd & nd & $<\mathrm{LOQ}$ & $<$ LOQ \\
\hline 0.097 & 0.045 & $<\mathrm{LOQ}^{* *}$ & nd & $<$ LOQ & nd \\
\hline 0.18 & 0.048 & nd & 0.25 & nd & $<\mathrm{LOQ}$ \\
\hline 0.13 & 0.073 & nd & 0.23 & nd & nd \\
\hline
\end{tabular}

* nd: not detected (< limit of detection);

$* *<$ LOQ: between limits of detection and quantification 


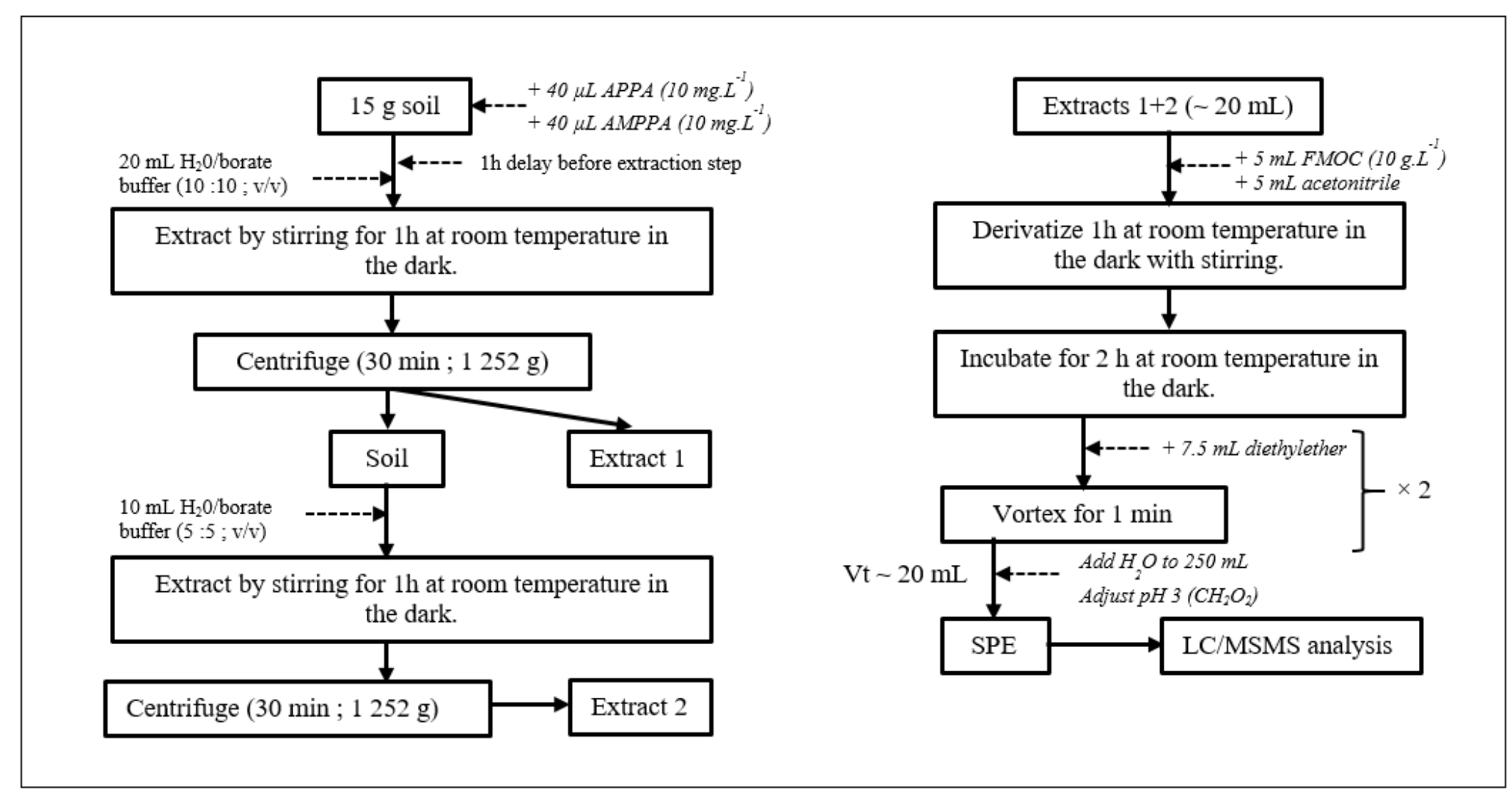

Figure 1. Summary of the Analytical method used for extracting soils 


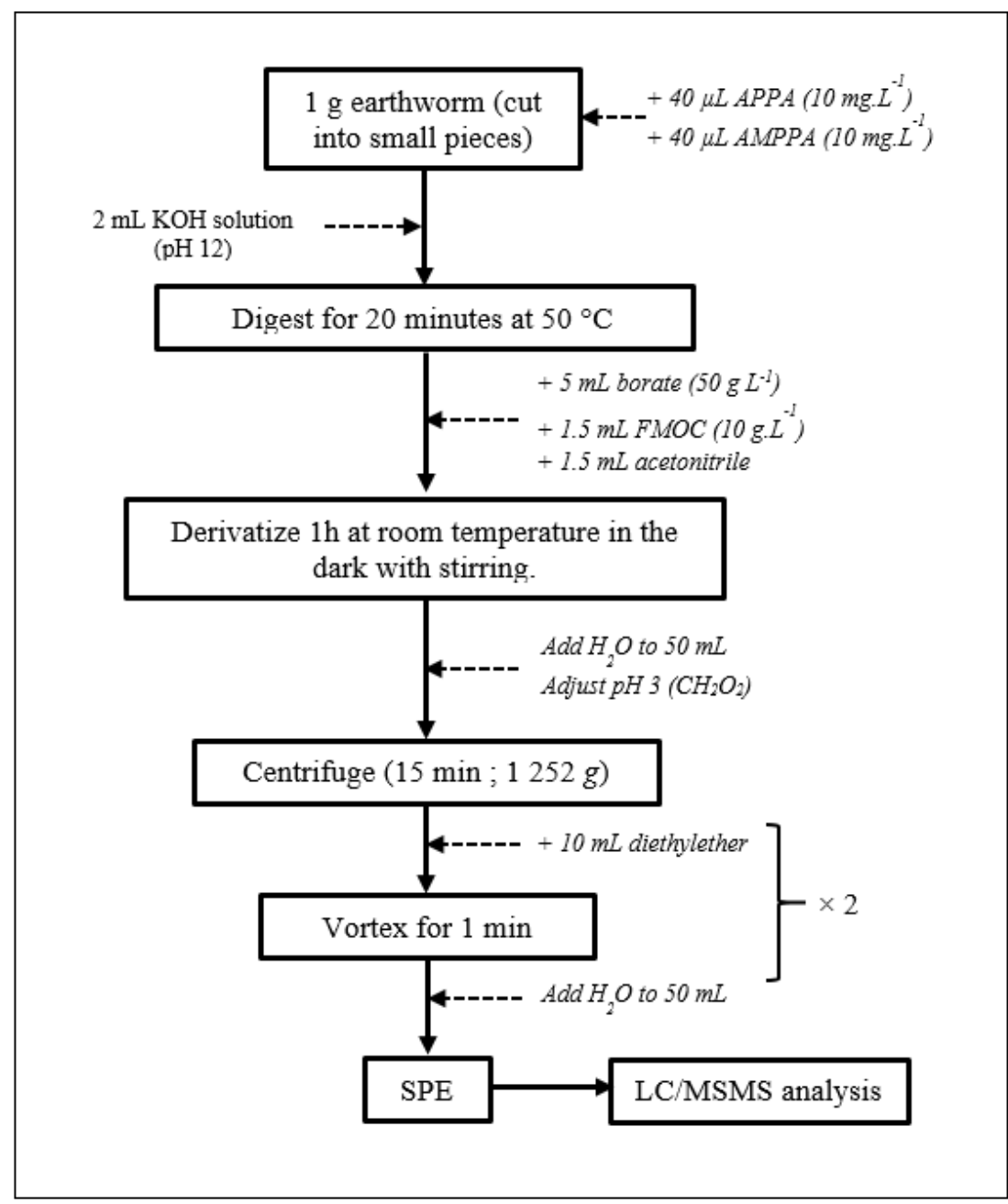

Figure 2. Summary of the analytical method used for earthworms

\begin{tabular}{|c|c|c|}
\hline AMPA & APPA & AMPPA \\
\hline $\mathrm{H}_{2} \mathrm{~N} \sim \underset{\mathrm{OH}}{\stackrel{\mathrm{O}}{\mathrm{P}}-\mathrm{OH}}$ & $\mathrm{H}_{3} \overbrace{\mathrm{H}_{2} \mathrm{~N}}^{\stackrel{\mathrm{O}}{\mathrm{II}}} \stackrel{\mathrm{O}}{\mathrm{P}}-\mathrm{OH}$ & $\overbrace{\mathrm{H}_{2} \mathrm{~N}}^{\stackrel{\mathrm{N}}{\mathrm{C}}-\mathrm{O}} \stackrel{\mathrm{O}}{\mathrm{CH}}-\mathrm{OH}$ \\
\hline $\mathrm{CH}_{6} \mathrm{NO}_{3} \mathrm{P}$ & $\mathrm{C}_{3} \mathrm{H}_{10} \mathrm{NO}_{3} \mathrm{P}$ & $\mathrm{C}_{4} \mathrm{H}_{12} \mathrm{NO}_{3} \mathrm{P}$ \\
\hline $\mathrm{MM}=111,04 \mathrm{~g} \mathrm{~mol}^{-1}$ & $\mathrm{MM}=139,09 \mathrm{~g} \mathrm{~mol}^{-1}$ & $\mathrm{MM}=153,12 \mathrm{~g} \mathrm{~mol}^{-1}$ \\
\hline (1-aminométhyl) phosphonic acid & (1- aminopropyl) phosphonic acid & (1- amino-2-metylpropyl) phosphonic acid \\
\hline
\end{tabular}

Figure 3. Structures of AMPA, APPA and AMPPA 

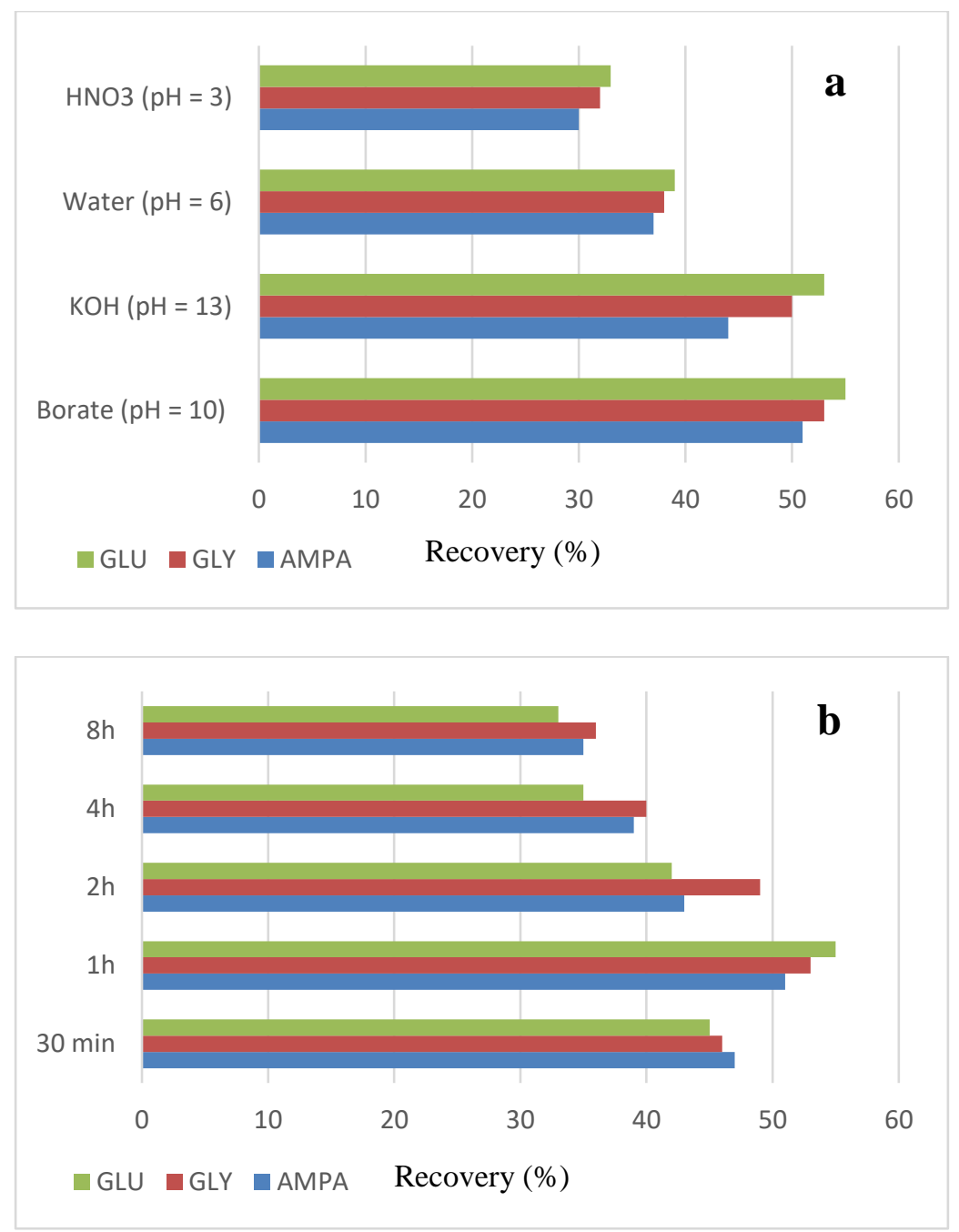

Figure 4. Recoveries of Glu, Gly and AMPA obtained during the optimization steps to test extraction solvents (a) and extraction times (b). 


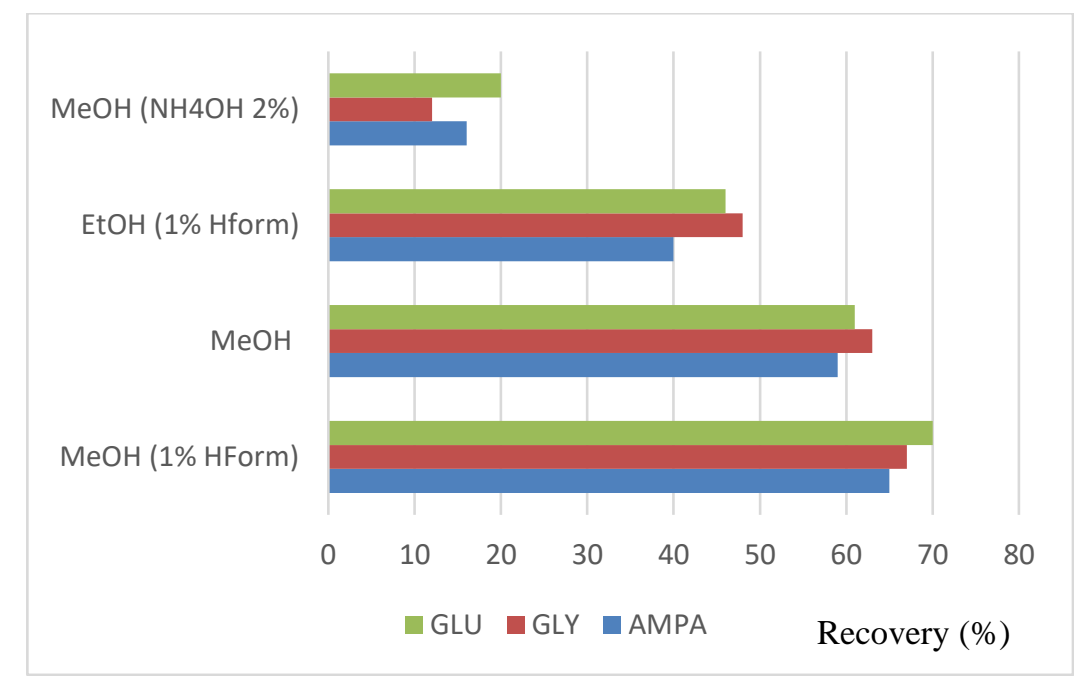

Figure 5. Glu, Gly and AMPA recoveries from SPE 


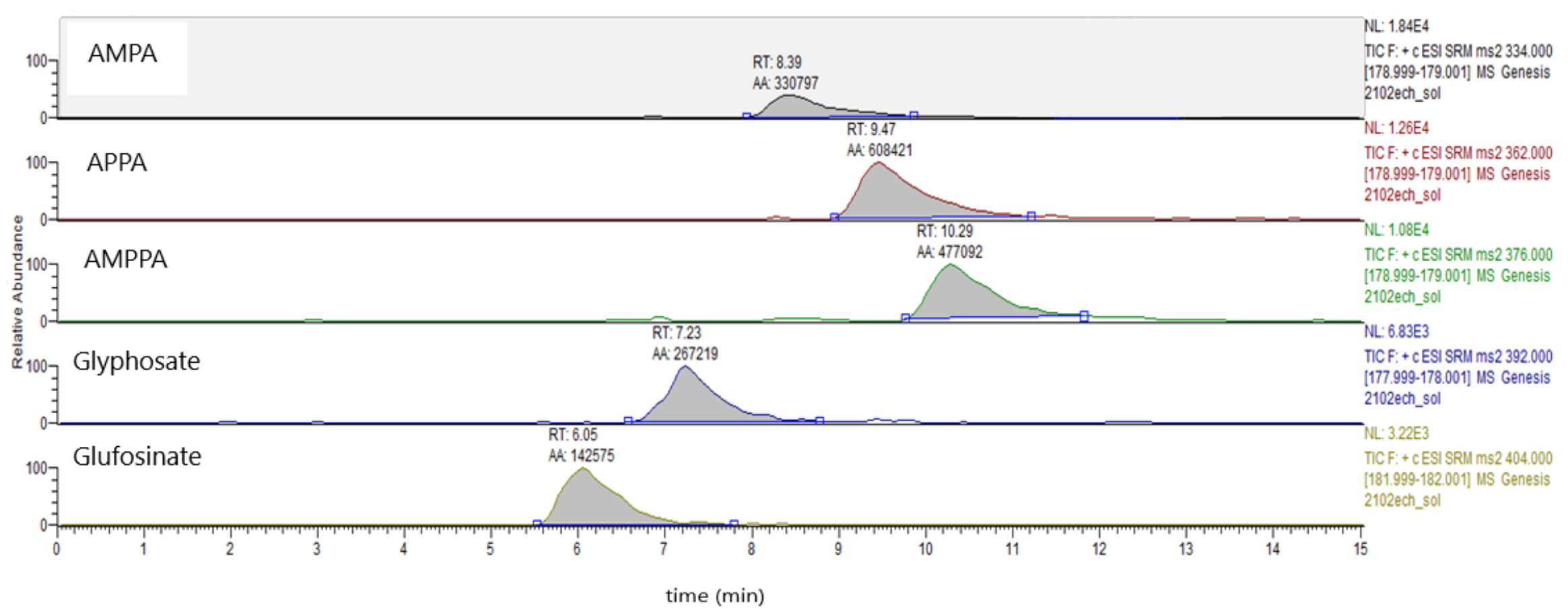

Figure 6. Chromatograms on the quantitation transitions of a soil sample where the compounds were determined as $0.070,0.069$ and $0.041 \mu \mathrm{g} \mathrm{g}^{-1}$ respectively for AMPA, GLY and GLU (the internal standards APPA and AMPPA being at $0.1 \mathrm{mg} \mathrm{L}^{-1}$ ). 